\title{
Investment as a Factor of Economic Growth
}

\author{
Aleksandr V. Menshikov \\ Yelena V. Kalabashkina \\ Sergey A. Zverev \\ Mari State University, Yoshkar-Ola, Russia \\ Email: G4836@yandex.ru
}

Doi:10.5901/mjss.2015.v6n3s7p259

\begin{abstract}
Investment is an important factor of economic growth. It defines the process of expanded reprocessing. Accumulation of social capital is possible due to investments. Investments contribute to additional revenue, which is determined by the state of general economic activity. Fluctuations in output affect the dynamics of investment over the business cycles. Theory and dynamics of investments are based on the principle of a "multiplier". The activity of investment resources as an economic factor is determined by its multiplying property. Its essence is that investment resources increase the equilibrium level of national output by an amount greater than the investment resources themselves. Modern economic growth theory was formed based on the ideas of optimality of the market system considered as a perfect self-regulating mechanism. Significant contribution to the development of economic growth theory was introduced by R. Solow. He developed two models: the model of factor analysis of economic growth sources and the model which reveals the relationship of savings, capital accumulation, investment and economic growth. Research investments as a factor of economic growth resulted in two ways out on the economic growth in Russia formulated in the article.
\end{abstract}

Keywords: investment, economic growth, macroeconomic balance, multiplier

\section{Introduction}

Investments represent one of the most important economic categories, one of the components of GNP, the most variable and at the same time determining the development of the economy. The amount of investment is very difficult to predict at the macro level if consumption is functionally related to the income, government spending and net export are fairly predictable. They can boost or drop sharply and suddenly. The volume of investments shrank by $100 \%$ during the Great depression in the United States. It reduced more than three times in Russia during the perestroika period (1992 to 1998). It was determined by several reasons, but the main one was that the savers lacked economic reasons to convert their funds into investments.

The leading role of investment in economic development is determined by the fact it results in accumulation of public capital, scientific and technological achievements implementation. Thus, a framework for expanding countries' manufacturing feasibility and their economic growth is created.

Investments determine the process of expanded reprocessing. New facilities constructions, houses erection, laying roads, and, consequently, providing employment depend on the process of investing or real capital formation.

The concept of multiplier-accelerator helps to understand balance problems typical of the correlation between investment and savings.

The great economists (A. Smith, D. Ricardo, J.-B. Say), who reviewed the investment process as the process of capital circulation in its various forms, introduced the foundations for the study of reprocessing proportions and the role of investment in this process. It should be emphasized that the investments as an economic category during the evolution of economic science are closely connected with the categories of sustainable growth, the economic system in general and macroeconomic equilibrium.

Macroeconomic equilibrium is one of the basic concepts of modern macroeconomic theory. General guidance on the sustainability and efficiency of the market economy as a system of economic relations based on a decentralized activity of economic entities is based on it. Keynesian and neo-Keynesian patterns of growth are based on perception of economic system stability and, therefore, focus on the problem of the advancing production potential of the economic 
system.

The investment demand is a property of a complex economic system that allows the system to adapt to changing external environment, helping to find a more stable position in the competitive environment (i.e., to increase the stock of organisational and economic sustainability).

That is why one should take into account the genesis of sustainability of the economic system and macroeconomic equilibrium (in close correlation with the category of "investments") when developing the modern concept of sustainable development and economic growth for the Russian Federation.

\section{Methods and Techniques}

Investments are an important factor that influences the growth of the gross national product.

Investment is highly volatile, and its variability is much more flexible than the variability of the gross national product. Let's take the lifetime of the equipment as an example. It should be noted that this factor does not obey some strict rules. From an economic point of view, everything here seems to be certain. It is necessary to change the equipment as long as the amortization period is over. In real life everything is much more complicated. But for some reasons known only to the entrepreneur, the validity of the equipment can be prolonged beyond the period of depreciation. It can be partially updated, updated on $1 / 2,1 / 4$, but the fixed capital may not be renewed for some period. In this connection the amplitude of investments in public production is determined by the entrepreneurs' decisions: they are either expanding or narrowing down. Production can be the subject for investing before its depreciation has expired, if it is required in terms of technological progress.

Irregularity is a characteristic feature of investment. Investments in a particular sector of the economy cannot be anticipated for the perspective in the near future. However, correctives can occur immediately. Technical and technological developments in one sector can cause rapid and intense investment in some other related sectors of the economy. For example, technical progress in the automobile industry always predetermines a flow of investment in the petrochemical industry. The same is true for all the interrelated sectors of the economy. The size of the current profit determines fluctuations in investment: stable profit makes stable investment; increase in profit results in the growth of investments. Drop in profits immediately limits investments. The volatility of profits increases the instability of investments.

Finally, instability of investment expectations determines their variability. Expectations are the subject to variability due to a large number of circumstances, including the state of the stock exchange. Fluctuations in the value of shares are created artificially by speculators to profit from speculative transactions with securities and cause instability in the entrepreneurs' and householders' investment policy.

The investment will pay the company additional revenue on condition it will be able to sell its products for more money. This means that aggregated output (or gross product), and consequently revenue is a very important factor for investment.

Investment, therefore, depends on the revenue, which in its turn is determined by the state of general economic climate. Some studies show that fluctuations of output affect the dynamics of investments in the course of business cycles.

Theory and dynamics of investments is based on the principle of "multiplier".

The concept of multiplier was introduced to economic theory by the English economist R. Kahn in 1931. He highlighted that state spending on social works undertaken by the F. Roosevelt's administration to reduce unemployment has led to a multiplier effect of employment. The expansion of social works results in the increase in employment more significantly than the increase in the number of employees directly involved in social works. For example, the workers employed for the highways engineering, increasing the demand for consumer goods, "cause" thus additional employment in industries specializing in the production of these goods in the "secondary" sector. In its turn, the growth of income and consumption in this group of workers will require expansion of consumer goods production related industries - the "tertiary" sector. The chain extends in descending order to other sectors. The multiplier effect will depend on the value of "initiating" action.

Modern economic growth theories were based on two sources: the neoclassical theory based on J. B. Say's theoretical views that were further developed in American economist J. B. Clark's works (1847-1938), and Keynesian theory of macroeconomic equilibrium.

The idea of the market system optimality considered as a perfect self-regulating mechanism that enables the best use of all production factors not only the individual economic agent, but also the economy as a whole is in the center of the neoclassical movement.

This balance is distorted in real economic life of the society. However, equilibrium modeling allows us to find the 
deviation of the actual processes from ideal ones. Cobb-Douglas' factor model and R. Solow's simple one-sector model of economic dynamics are the well-known.

Cobb-Douglas' factor model shows the interaction and substitutability of labour and capital, the extent to which the product depends in its creation on this or that factor, as well as the combination to achieve the production maximum at the lowest cost.

The same amount of growth in national product can be obtained as a result of either increased investment or expansion in the use of labour. So, production functions predetermine the technological combination of these factors under the particular circumstances.

Cobb-Douglas' model has been modified during further studies made by economists (E. Denison, R. Solow) and developed by other growth factors introduction: age of fixed capital, scale of production, workers' skills, the working week duration.

Significant contribution to the development of economic growth theory was made by R. Solow. He developed two models: the model of factor analysis of economic growth sources and the model, which reveals the relationship of savings, capital accumulation, investment and economic growth. Cobb-Douglas' production function is the basis of the first model. It was modified by entering another factor - the level of technology development:

$\mathrm{Q}=\mathrm{F}(\mathrm{K}, \mathrm{L}, \mathrm{T})(1)$

where $\mathrm{Q}$ is output; $\mathrm{K}$ is capital; $\mathrm{L}$ is labor (in the form of wages); $\mathrm{T}$ is the level of technological development.

Solow suggested that the change in technology leads to the same increase in the marginal product of $\mathrm{K}$ and $\mathrm{L}$, i.e.

$\mathrm{Q}=\mathrm{TF}(\mathrm{K}, \mathrm{L}),(2)$

where $F(K, L)$ is the usual neoclassical Cobb-Douglas' production function.

The growth of output can be represented as follows:

$\mathrm{s} Q=\mathrm{sTF}(\mathrm{K}, \mathrm{L})+\mathrm{s} \mathrm{K} \cdot \mathrm{TFK}+\mathrm{s} \mathrm{L} \cdot \mathrm{TFL}(3)$

This means that the increase in output is proportional to the technology growth rate (ST), gross fixed capital formation (sK) and the growth rate of labor input (sL). The share of capital change in the release is equal to $\mathrm{s}$ multiplied by the marginal product of capital (TFK), while the share of labour in output is equal to $s$, multiplied by the marginal product of labour (TFL).

The growth rate of output can be represented by the equation:

$\mathrm{s} Q / \mathrm{Q}=\mathrm{s} T / \mathrm{T}+\mathrm{SL}+\mathrm{s} \mathrm{L} / \mathrm{L}+\mathrm{Sk}+\mathrm{SK} / \mathrm{K}$

As it can be seen, the growth rate of release $s \mathrm{Q} / \mathrm{Q}$ depends on:

- the pace of technological progress $s T / T$

- the rate of labor input growth L s/ L multiplied by the share of wages (labour) in total production SL (the share of wages in the product is defined as the ratio of nominal wages to the price issue);

- the growth rate of capital - s K/K , multiplied by the share of capital in output SK.

If the share of labor and capital to output is measured on the basis of labour productivity, capital per worker and capital productivity, the contribution of technical progress is represented as the remainder after deducting from the increased production of the share obtained by the increase of labor and capital, i.e. - s T/T is the so-called Solow's residue, which expresses the share of economic growth through technological progress, or progress in knowledge.

Another Solow's model shows the relationship between savings, capital accumulation and economic growth.

If we denote the production per employee q, the quantity of capital per worker - k (capital - or capital-labour ratio), the production function takes the form:

$q=\operatorname{TF}(k)$.

The main factors constraining investment activity currently include:

- great dependence of the national economy, public finance and balance of payments on external economic conditions in the existing structure of GDP;

- excessive administrative barriers for entrepreneurs;

- insufficient legal protection of domestic and foreign investors, weak law enforcement practices;

- commercial lending high price, despite a noticeable decline in rates in the financial market;

- the lack of effective mechanisms of savings into investments transformation;

- underdevelopment of the stock market.

\section{Results}

The creation of conditions for sustainable economic growth that can be achieved by improving the use of resources involved and the existing economic potential is one of the key objectives in the development of any economic system. 
The significant increase in investments and improvement of their quality parameters is of fundamental importance. Growth is the ultimate goal of any economy irrespective of its nature. Defining this goal makes it possible to achieve two results simultaneously: satisfaction with the individual and collective needs growth (raising living standards) and creating the most favorable conditions to participate in international competition.

The activity of investment resources as an economic factor is determined by their multiplying property, which essence is that investment resources increase the equilibrium level of national output by an amount greater than the investment resources.

The main factors of economic growth are population, investment, innovation and development exchange. The search for the optimal combination of these factors and conditions for their use is the subject of a deliberate state policy in the medium-term planning.

To achieve sustained and balanced growth in order to up-date and to catch-up development, the transition to the innovative stage of economic development and the creation of appropriate infrastructure are the main tasks on the way of increasing economic growth in Russia.

To implement the strategic objectives Russia is interested not only in economic growth but in high growth rate not less than $5 \%$ per year that significantly exceeds the growth rate of developed countries.

General conditions for the trajectory of sustained growth for countries with emerging markets include:

1) Focus on external demand, the openness of the economy. Poorly developed and limited domestic market does not create sufficient conditions for the existence of market incentives and the search for potential strengths of the economy.

2) Market resources distribution. The free flow of resources and the capital are fundamental requirements of a successful strategy for sustainable growth. However, the main point is that the state should make the market full, but not to substitute the market. The government intervention should not distort market-based incentives. This is the only case when it would contribute to success, not to impede it.

3) High savings rate. The level of accumulation in the catch-up development countries is at least 25-30\% of GDP. This conclusion is of fundamental importance for the analysis of economic growth prospects in Russia and for policies design aimed at its promotion. Recently, the level of investment in the fixed capital in Russia has remained at the level of $20-22 \%$ which still does not meet the requirements of sustainable growth.

4) Macroeconomic stability. The countries with sustainable growth experienced different periods. Macroeconomic conditions should be favorable for the existence of market-based incentives that presuppose competitive currency. Inflation rate has to be a simple number (up to 10\%). Too rapid growth of public expenses poses a threat to the macroeconomic stability and unreasonably increases the role of the state in the economy.

\section{Discussion}

At present the Russian economy does not meet the requirements of entering the path of sustainable growth in many aspects.

Let's formulate a way out to economic growth in the Russian context taking into account general terms:

1. Focus on decline in inflation will change the mechanism of money supply, increase the tendency for long-term savings and investment as well as will reduce the economy dependence on external markets. Achieving a consistently positive refinancing rate and its reduction to simple numbers is the main purpose of decline in inflation. Such a policy will change the mechanism of money supply. The role of the foreign exchange market will decrease while the role of the interest rate will increase.

2. Removal of institutional barriers that restrain economic growth such as: high barriers to enter the markets, excessive and inefficient regulation, the tax burden decline, corruption, inequality of market agents. The enhancement of the regulatory framework is necessary for these obstacles removal.

3. Business climate improvement aimed to remove the most sensitive to economic growth institutional constraints and to attract investments.

4. Investment in the human capital. The concept of human capital explores the relationship between investments in people and human capital accumulation, on the one hand, and incomes received by individuals, firms and the state from these investments, on the other. Human capital is the integrity of knowledge, skills, abilities, and individual's performance capabilities.

5. To lessen the impact of negative factors and maximize the effect of the advantages.

6. To encourage savings and to increase the accumulation rate.

Reviving the domestic economy is not sustainable growth. The economic situation is characterized only by some 
positive trends in the dynamics of the main socio-economic indicators. Having strong investment potential and related resources, the Russian economy is characterized by low investment activity and has no stable tendency for growth. The reasons are the following:

- misguided economic policy and strategic miscalculations resulted in capital outflow;

- the destruction in the scientific and production potential of the country;

- reducing the competitiveness of the national economy;

- destruction of the state financial system due to an erroneous monetary policy and the monetary authorities' creation of "financial pyramids", which entailed the actual bankruptcy of the state, its sharp weakening, involvement in the debt crisis, and monetary circulation breakdown;

- the Russian investment projects underestimation by investors; their erroneous rejection of numerous beneficial projects as inefficient ones due to the mismatch of discount rate standards (NPV, IRR, PB) to the development processes and real growth of modern industries, especially in the area of innovative products and services creating;

- weak dissemination of regulation methods in the industries that results in low innovation activity, decreases investment efficiency and the competitiveness of the Russian companies and industries on the whole;

- the system of legislative and public control over the activities of senior government officials and executive authorities destruction; bureaucracy in management systems, including the regulation of investment flows.

However, the main thing is to increase the investment attractiveness and investment activity, and on this basis, economic growth is hampered by the lack of a single, clearly-defined strategy of the state development.

\section{Conclusion}

The Strategy of business climate improving and the Strategy of increasing investment attractiveness are the key elements when a new model of economic growth would be formed. They are necessary to solve the major problems of the Russian economy development at the modern stage. Dependence on external markets, the lack of "long" money and qualitative investments, domestic prices rapid growth, the Russian goods low competitiveness are among these problems. All these problems cannot be solved without improving the quality of the business environment and investment climate.

Any type of economic growth, whether the increase in scale of production (extensive type of economic growth) or the quality (intensive type), requires additional investment. The possibility of the investment process and its implementation is becoming the main engine and the controller of economic growth.

The mechanism of economic growth interaction and investment formulated by $P$. Samuelson in the form of "accelerator principle" runs: real GDP growth implies an increase in real investment, in its turn, the rise of real investment causes GDP growth.

Table 1. The real volume of GDP billion rubles

\begin{tabular}{|c|c|c|c|c|}
\hline & $\begin{array}{c}\text { GDP, billion } \\
\text { rubles. }\end{array}$ & $\begin{array}{c}\text { GDP, in \% according to the } \\
\text { definite period }\end{array}$ & $\begin{array}{c}\text { the Index of goods and services output by basic types of } \\
\text { economic activity, \% }\end{array}$ & $\begin{array}{c}\text { Index deflator } \\
\text { GDP, } \%\end{array}$ \\
\hline 2014 year & & & & 100,30 \\
\hline 1quarter & 15992,00 & 100,90 & 100,40 & 108,30 \\
\hline 2 quarter & 17697,20 & 100,80 & 100,70 & 109,90 \\
\hline 3 quarter & 18703,40 & 100,70 & & 105,90 \\
\hline 4 quarter & & & & \\
\hline
\end{tabular}

In the third quarter of 2014 the growth rate of GDP for the corresponding period of the previous year remained in the terms of positive values of $0.7 \%$ due to the record harvest and high dynamics of the manufacturing industries, but seasonally purified indicators of the GDP growth rates were already zero. In the fourth quarter, according to the Ministry of economic development, the growth rate of GDP for the corresponding period of the previous year was also close to zero, as well as the indicators of seasonally purified dynamics. GDP growth was 0.6 percent on the whole in 2014.

Observed since the middle of 2012 this slowdown was originally associated with the investment pause caused by the debt crisis spread in the Eurozone. The structural problems caused by an early increase in costs primarily associated with workforce were traced with the development of economic slowdown. It resulted in the gross profit share in GDP reduction and, as a result, loss of resources for investment growth. In the end, the investment pause dragged on, and 
new factors limiting economic growth were added in 2014. The conflict in the Ukraine, imposed economic sanctions against Russia and oil prices falling since mid-2014 have led to the increased uncertainty, reduced incomes and a sharp deterioration in business confidence. The restriction of access to international capital markets and the tightening of monetary policy caused a rise in the cost of borrowing that mostly led to negative impact on investment demand and consumer confidence, having caused an increased capital runoff, ruble weakening and an inflation spurring.

The following measures could be offered to solve the problem of further economy regulation:

- to strengthen fiscal policy not only by increasing the costs process but also due to the stronger decrease in taxes in the manufacturing sector;

- to update macroeconomic policy having created the center that will coordinate different government agencies activities; implementation of anti-corruption mechanisms taking into account international experience;

- more attention should be paid to the stock market development, self-financing, attracting money by means of the IPO, as well as by other stock market tools;

- the banking system should be improved, should develop further, should offer much service to the population; small and medium-sized businesses are the weakest elements of our economy;

- to use the latest scientific developments and achievements: investors stimulate the economic growth of the country implementing the results of scientific and technical process. At the same time the development and growth of the economy are an incentive to make business income and economically active population work, making profit to the owners and the state, thereby determining the investment activity in the country.

\section{References}

Sharpe, W.F., \& Alexander, G.J. (1990). Investments. (4 th ed.). Prentice Hall International, Inc. Van Horne, J.C. (1995). Financial Management and Policy. (10 th ed.). New York: Prentice- Hall. Williams, J.B. (1938). The Theory of Investment Value. Cambridge, Mass Harvard Univ Press.

Boudhiaf Messaoud, Zribi El Ghak Teheni. (2014). Business regulations and economic growth: What can be explained? International Strategic Management Review 2, 112 , 69-78.

Zverev, S. A. (2013). The Concept of Middle Class in Russia. Collection of scientific works of the post "Modern Solutions of Modern Science". Vol.3. Yoshkar-Ola, . P. 89-96.

Kalabashkina, E. V. (2014). The Criterion of Efficient Use of Budget Funds. Collection of scientific works of the post-graduate students "Modern Solutions of Modern Science". Vol.4. Yoshkar-Ola, 2014. P. 126-131.

Menshikov, V. A. (2014). Problems of Modern Economics: Collection of the interregional scientific-practical conference / Mari State University. - Yoshkar-Ola, Vol. 21. 312 p.

Nurmuhametov, I. M. (2014). The III-d All-Russian Scientific-Practical Conference on the Basis of Part-time Internet forum "Market Transformation of the Russian Economy: Problems, Perspectives, Ways of Development". Scientific section: Actual Problems of Theory and Practice Banking and Insurance. Yoshkar-Ola: MOSI, S. 